\title{
End growth results analysis related to Risser score, Cobb degrees, and curve types at the beginning of the treatment
}

\author{
S Donzelli ${ }^{*}$, F Zaina', S Negrini ${ }^{2,3}$ \\ From 9th International Conference on Conservative Management of Spinal Deformities - SOSORT 2012 \\ Annual Meeting \\ Milan, Italy. 10-12 May 2012
}

\section{Background}

Scoliosis treatment is the science of prediction and estimation.The strategy is based on the magnitude, and pattern of the deformity, both related to age and Risser Score, to predict the potential progression. The efficacy of the conservative treatment of scoliosis is known, and analysis of factors potentially influencing the results is surely interesting.

\section{Aim}

To assess the final results stratified according to curve magnitude, Risser score, curves type, gender and age, of a prospective set of patients treated in a centre fully dedicated to the conservative treatment of Adolescent Idiopathic Scoliosis AIS.

\section{Method}

Study Design: Retrospective study. Population. 388 (31 males) patients respecting these inclusion criteria: AIS diagnosis, Risser test 0-3; all Cobb degrees; no prior treatment; who had reached the end of treatment since our institute database start in 2003. Methods: Clinical and radiographic (Cobb degrees) data at the beginning of treatment have been compared to end growth results. Treatments: All patients were treated respecting SOSORT standard of conservative treatment with observation, exercises, soft and rigid braces.

\section{Results}

At the start of treatment worst curves corresponded to highest Risser test. With treatment, the percentage of

${ }^{1}$ ISICO (Italian Scientific Spine Institute), Milan, Italy

Full list of author information is available at the end of the article unchanged patients remained almost stable (40-50\%), while progression was higher in Risser 0 then at other Risser stages (16.6\% vs 7.4-9.9\%); highest rates of improvement appeared at Risser 1 or 3 (45-47\% vs 33$39 \%)$. Patients who begin the therapy at Risser 0 have a higher probability to end treatment under $30^{\circ}$ Cobb. The probability of curve progression is highest at the lowest and highest initial sizes of curve (i.e. below $20^{\circ}$ or over $40^{\circ}$ ).In this sample of treated patients, the rate of progressed curves was very low, with a high rate of stabilized and improved curves. The total number of patients who finished with curves over $30^{\circ} \mathrm{C}$ increases proportionally with a starting Risser Score. Considering curve's type, age and gender we didn't find differences in final results.

\section{Conclusion}

The efficacy of conservative treatment has been demonstrated in some previous studies. Our data confirms this aspect, with a trend of all final results $\left(82.6 \%\right.$ below $\left.30^{\circ} \mathrm{C}\right)$, telling us that therapy is the most important predictive factor. As expected, the lower the age and Risser at start the lower the curve magnitude, and the best the final results, confirming the importance of early AIS detection.

\section{Author details \\ ${ }^{1}$ ISICO (Italian Scientific Spine Institute), Milan, Italy. ${ }^{2}$ University of Brescia, Brescia, Italy. ${ }^{3}$ RCCS Don Gnocchi, Milan, Italy.}

Published: 3 June 2013

\section{References \\ 1. Coillard C, Vachon V, Circo AB, Beausejour M, Rivard CH: Effectiveness of the SpineCor brace based on the new standardized criteria proposed by the scoliosis research society for adolescent idiopathic scoliosis. J Pediatr Orthop 2007, 27(4):375-379.}


2. Lonstein JE, Carlson JM: The prediction of curve progression in untreated idiopathic scoliosis during growth. J Bone Joint Surg Am 1984,

66(7):1061-1071.

3. Negrini S, Atanasio S, Zaina F, Romano M, Parzini S, Negrini A: End-growth results of bracing and exercises for adolescent idiopathic scoliosis. Prospective worst-case analysis. Stud Health Technol Inform 2008, 135:395-408.

doi:10.1186/1748-7161-8-S1-010

Cite this article as: Donzelli et al:: End growth results analysis related to Risser score, Cobb degrees, and curve types at the beginning of the treatment. Scoliosis 2013 8(Suppl 1):010.

Submit your next manuscript to BioMed Central and take full advantage of:

- Convenient online submission

- Thorough peer review

- No space constraints or color figure charges

- Immediate publication on acceptance

- Inclusion in PubMed, CAS, Scopus and Google Scholar

- Research which is freely available for redistribution

Submit your manuscript at www.biomedcentral.com/submit
() Biomed Central 